\title{
Originals
}

\section{Effect of physiological elevation of plasma growth hormone levels on ketone body kinetics and lipolysis in normal and acutely insulin-deficient man}

\author{
U. Keller, H. Schnell, J. Girard and W. Stauffacher \\ Department of Medicine and Department of Research, University Hospital Basel, Switzerland
}

\begin{abstract}
Summary. The effect of physiological elevation of growth hormone levels on ketone body kinetics was determined using a ${ }^{14} \mathrm{C}$-ketone body tracer technique in normal and acutely insulin-deficient man. Changes of ketone body production and metabolic clearance rates during growth hormone infusion (plasma levels of approximately $25 \mu \mathrm{g} / \mathrm{l}$ ) were measured during basal conditions and during heparin-induced elevation of non-esterified fatty acid levels. Growth hormone administration to six subjects fasted overnight resulted in an increase in ketone body production which exceeded that observed in nine control subjects $\left(5.5 \pm 0.5\right.$ versus $3.1 \pm 0.1 \mu \mathrm{mol} \cdot \mathrm{kg}^{-1} \cdot \mathrm{min}^{-1}$, $p<0.025$ ) after elevation of plasma non-esterified fatty acids. Growth hormone infusion increased glycerol and non-esterified fatty acid concentrations indicating enhanced lipolysis. During somatostatin-induced acute insulin deficiency $(n=7)$, growth hormone enhanced the increase in total ketone body production observed in six subjects receiving somatostatin
\end{abstract}

alone $\left(8.4 \pm 0.8\right.$ versus $\left.4.1 \pm 0.7 \mu \mathrm{mol} \cdot \mathrm{kg}^{-1} \cdot \mathrm{min}^{-1}, p<0.01\right)$. Total ketone body metabolic clearance decreased by $50 \%$ during somatostatin and remained uninfluenced by growth hormone. Non-esterified fatty acids and glycerol levels increased during somatostatin, and growth hormone failed to alter nonesterified fatty acid levels significantly. The results demonstrate a stimulatory effect of high physiological growth hormone levels on ketogenesis which is largely explained by an enhancement of lipolysis and thus increase in substrate supply for ketogenesis. Growth hormone administration during acute insulin deficiency enhanced ketogenesis in the absence of alterations in plasma non-esterified fatty acid levels, suggesting a direct hepatic ketogenic effect.

Key-words: Growth hormone, ketone bodies, ketogenesis, nonesterified fatty acids, glycerol, diabetes, insulin, glucagon, somatostatin.
Several lines of evidence suggest a role for growth hormone in the regulation of ketone body metabolism in man. Various physiological and pathological conditions are associated with elevated concentrations of ketone bodies and growth hormone such as exercise [1], poor metabolic control [2], ketoacidosis [3] and post-hypoglycaemia ketosis [4] in diabetic subjects, and alcoholic ketoacidosis [5]. Administration of pharmacological amounts of growth hormone induced ketosis in animals [6-8]. Several studies in man demonstrated lipolytic and ketogenic effects of pharmacological doses of growth hormone [9-11]. An increase in ketone body concentrations by physiological growth hormone levels has been reported in normal $[12,13]$ and diabetic $[14,15]$ man. Ketone body concentrations did not always parallel non-esterified fatty acid levels $[12,15]$, suggesting a direct hepatic ketogenic effect of growth hormone. However, ketone body production rates were not measured and growth hormone effects on ketone body utilization could not be excluded.
The influence of growth hormone on ketone body production and peripheral clearance has not yet been investigated. We therefore studied the effect of growth hormone levels as observed in stress conditions on ketone body kinetics and lipolysis in normal and in acutely insulin-deficient man.

\section{Methods}

\section{Patients and procedures}

Twenty-eight healthy subjects (aged 50-66 years; 20 women and 8 men) volunteered to participate. Their weight was within $15 \%$ of ideal body weight and averaged $65 \pm 2 \mathrm{~kg}[16]$. They were on no medication. An oral glucose tolerance test and a blood chemistry profile (SMA 12 Technicon, Tarrytown, New York) were within normal limits before the study. After their usual meal at $19.00 \mathrm{~h}$ the evening before the study, they remained fasted until beginning of the study at $07.30 \mathrm{~h}$. A Teflon cannula was inserted into an antecubital vein for infusion, and a Butterfly needle (1.1 $\mathrm{mm}$ inner diameter) into a hand vein of the contralateral arm which was kept in a warming chamber at $60^{\circ} \mathrm{C}$ [17]. 
Table 1. Basal ketone body kinetics, blood substrate and hormone levels in the four study protocols

\begin{tabular}{|c|c|c|c|c|}
\hline & $\begin{array}{l}\text { Saline } \\
\text { infusion } \\
(n=9)\end{array}$ & $\begin{array}{l}\text { Growth hormone } \\
\text { infusion } \\
(n=6)\end{array}$ & $\begin{array}{l}\text { Somatostatin } \\
\text { infusion } \\
(n=6)\end{array}$ & $\begin{array}{l}\text { Somatostatin }+ \\
\text { growth hormone } \\
\text { infusion } \\
(n=7)\end{array}$ \\
\hline Total ketone body concentration $(\mu \mathrm{mol} / \mathrm{l})$ & $290 \pm 79$ & $332 \pm 135$ & $248 \pm 66$ & \pm 66 \\
\hline Acetoacetate concentration $(\mu \mathrm{mol} / \mathrm{l})$ & $114 \pm 29$ & $130 \pm 43$ & $89 \pm 22$ & $98 \pm 20$ \\
\hline$\beta$-hydroxybutyrate concentration $(\mu \mathrm{mol} / \mathrm{l})$ & $160 \pm 50$ & $182 \pm 86$ & $145 \pm 36$ & $120 \pm 45$ \\
\hline$\beta$-hydroxybutyrate-acetoacetate concentration ratio & $1.21 \pm 0.20$ & $1.55 \pm \quad 0.41$ & $1.64 \pm 0.20$ & $1.10 \pm 0.23$ \\
\hline Total ketone body uptake $\left(\mu \mathrm{mol} \cdot \mathrm{kg}^{-1} \cdot \min ^{-1}\right)$ & $4.1 \pm 0.9$ & $4.1 \pm 1.0$ & $3.8 \pm 0.9$ & $3.7 \pm 0.8$ \\
\hline Total ketone body metabolic clearance rate $\left(\mathrm{ml} \cdot \mathrm{kg}^{-1} \cdot \mathrm{min}^{-1}\right)$ & $15.9 \pm 0.9$ & $15.9 \pm 2.4$ & $15.6 \pm 1.0$ & $17.5 \pm 1.0$ \\
\hline Plasma growth hormone ( $\mathrm{\mu g} / \mathrm{l})$ & $1.7 \pm 0.3$ & $3.0 \pm 0.7$ & $2.0 \pm 0.2$ & $2.8 \pm 0.6$ \\
\hline Plasma insulin $(\mathrm{mU} / \mathrm{l})$ & $8.9 \pm 1.6$ & $9.9 \pm 1.2$ & $10.5 \pm 3.2$ & $8.7 \pm 1.0$ \\
\hline Plasma glucagon (ng/l) & $134 \pm 26$ & $145 \pm 21$ & $122 \pm 19$ & $165 \pm 19$ \\
\hline Plasma NEFA $(\mathrm{mmol} / 1)$ & $0.85 \pm 0.06$ & $0.93 \pm \quad 0.09$ & $0.91 \pm 0.09$ & $0.76 \pm 0.07$ \\
\hline
\end{tabular}

Results are expressed as mean \pm SEM of the average of three values

Thereafter a primed continuous infusion of $150 \mu \mathrm{Ci} 3-{ }^{14} \mathrm{C}$-acetoacetate was started. The tracer was allowed to equilibrate for $60 \mathrm{~min}$ [18], and the first sample of the basal period was collected.

Four protocols were performed: (1) saline infusion (controls, $n=$ 9); (2) growth hormone infusion at $80 \mathrm{ng} \cdot \mathrm{kg}^{-1} \cdot \min ^{-1}(n=6)$; (3) somatostatin $\left(6.5 \mu \mathrm{g} \cdot \mathrm{kg}^{-1} \cdot \mathrm{h}^{-1}, n=6\right)$ to produce insulin (and glucagon and growth hormone) deficiency; and (4) somatostatin + growth hormone at $80 \mathrm{ng} \cdot \mathrm{kg}^{-1} \cdot \min ^{-1}(n=7)$. The hormones were infused for $170 \mathrm{~min}$ after a basal period of $30 \mathrm{~min}$. To study the effects of growth hormone on ketogenesis at basal and elevated substrate levels, non-esterified fatty acid (NEFA) concentrations were raised acutely by injecting 5000 units of heparin (Liquemine, Roche, Basal) 120 min after beginning of the growth hormone infusion. The study protocol was approved by the Ethics Committee of the Department of Medicine, University Hospital, Basal.

\section{Infusions}

Sodium $3{ }^{-14} \mathrm{C}$-acetoacetate was prepared from $3{ }^{14} \mathrm{C}$-ethyl-acetoacetate as described previously [18]. The radiochemical purity of the ${ }^{14} \mathrm{C}$ acetoacetate infusion was $80 \pm 1 \%$. Human growth hormone (Crescormon, Kabi, Stockholm) was diluted with $0.145 \mathrm{~mol} / 1 \mathrm{NaCl}$ to which albumin (Swiss Red Cross, Berne) was added to provide a final concentration of $1 \%(\mathrm{w} / \mathrm{v})$. Somatostatin (kindly provided by Serono, Freiburg i. Br., FRG) was dissolved in $\mathrm{NaCl}$ solution $(0.145 \mathrm{~mol} / \mathrm{l})$.

\section{Analyses and calculations}

Blood concentrations of ${ }^{14} \mathrm{C}$-acetoacetate and ${ }^{14} \mathrm{C}$-total ketone body were determined individually by converting the ketone bodies to ${ }^{14} \mathrm{C}$ acetone according to the method of Mayes and Felts [19] with a minor modification [20]. Blood acetone was measured by headspace analysis using gas chromatography [21]; blood acetoacetate, $\beta$-hydroxybutyrate and glycerol were determined using microfluorometric techniques as described previously [18]. Plasma NEFA were measured by a radiochemical method [22]; plasma insulin [23], growth hormone [24] and glucagon [25] by radioimmunoassay. For the latter, the pancreatic glucagon-specific antibody 4305 , kindly provided by Dr. J. Holst, Copenhagen, was employed [26]. Plasma glucose concentrations were determined using a YSI glucose analyser (Yellow Springs Instruments, Yellow Springs, Ohio, USA). Recovery of ${ }^{14} \mathrm{C}$-acetoacetate added to non-radioactive blood was $87 \pm 2 \%$, that of ${ }^{14} \mathrm{C}-\beta$-hydroxybutyrate $83 \pm 1 \%$, and corrections were made accordingly.

Total ketone body turnover rates were determined using the combined specific activity of total ketone bodies [18]. Ketone body turn- over rates of each time point were calculated by the method of moving average using the specific activity of ketones of three consecutive blood samples and regression analysis in the calculation [17]. Statistical analyses were performed using Student's two-tailed t-test for paired and for unpaired data.

\section{Results} Basal ketone body kinetics, substrate and hormone levels
in normal subjects fasted overnight

During the 30-min control period, total ketone body kinetics, and concentrations of insulin, glucagon and growth hormone, NEFA and glycerol were similar in the four study protocols (Table 1).

\section{Effect of growth hormone on ketone body kinetics and lipolysis in normal subjects}

Administration of growth hormone resulted in an increase in ketone body production which was statistically significant compared to the last pre-infusion value from 60 min onwards (Fig. 1, $p<0.01$ ).

The increase in ketone body production was greater during the growth hormone than during saline infusion after heparin-induced elevation of NEFA levels from 135 min onwards. Administration of heparin resulted in a significant increase in ketogenesis; within $30 \mathrm{~min}$ total ketone body production increased during growth hormone by $3.6 \pm 0.4$ versus $2.3 \pm 0.4 \mu \mathrm{mol} \cdot \mathrm{kg}^{-1} \cdot \mathrm{min}^{-1}$ during saline $(p<0.05)$. The fact that ketone body production was already increasing at the time of heparin injection $(120 \mathrm{~min})$ is due to the mode of calculation of ketone body kinetics using the moving average method (see Methods). Total ketone body uptake showed a similar increase to that of production but with a slight delay, causing the increase in ketone body concentration. The metabolic clearance rate of total ketone bodies de- 


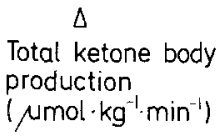

$\Delta$

Total ketone body uptake ( $\mathrm{Nmol} \cdot \mathrm{kg}^{-1} \cdot \mathrm{min}^{-1}$ )

$\Delta$

Total ketone body metabolic clearance $\left(\mathrm{ml} \cdot \mathrm{kg}^{-1} \cdot \mathrm{min}^{-1}\right)$

$\triangle$

Total ketone body concentration ( $\mathrm{umol} / \mathrm{l})$
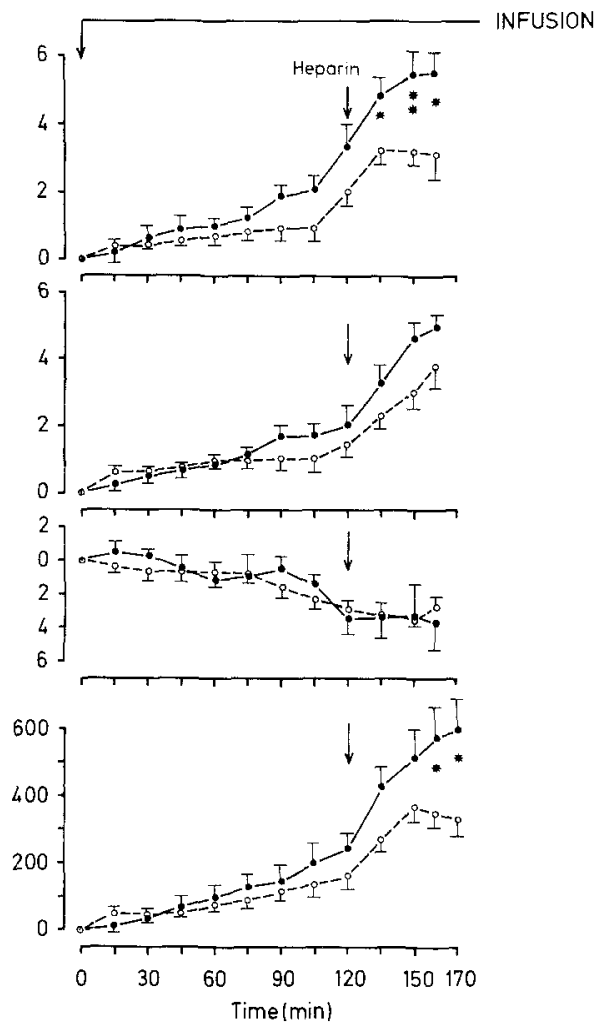

Fig. 1. Changes in total ketone body production, uptake, metabolic clearance rate and total ketone body concentration during infusion of growth hormone $\left(80 \mathrm{ng} \cdot \mathrm{kg}^{-1} \cdot \mathrm{min}^{-1}\right.$, solid line) or saline (dashed line) in normal subjects at $120 \mathrm{~min}, 5000$ units of heparin were injected. The results are expressed as mean \pm SEM. $* p<0.05 ; * * p<0.025$ between groups

creased slightly but significantly $(-17 \pm 3 \%)$ during saline $(p<0.01)$, and similarly during growth hormone $(-22 \pm 7 \%)$. Blood $\beta$-hydroxybutyrate concentrations increased during $170 \mathrm{~min}$ of growth hormone infusion by $419 \pm 69 \mu \mathrm{mol} / 1 \quad(p<0.001)$, and acetoacetate by $161 \pm 23 \mu \mathrm{mol} / 1(p<0.001)$. In comparison, blood $\beta$-hydroxybutyrate concentrations increased less in the control subjects by $240 \pm 49 \mu \mathrm{mol} / \mathrm{l}$, and acetoacetate by $86 \pm 11 \mu \mathrm{mol} / 1(p<0.05$ and $p<0.01$ respectively, compared with the growth hormone infusion study). Blood acetone concentrations increased similarly in both protocols (by $14 \pm 5$ and $18 \pm 6 \mu \mathrm{mol} / 1, p<0.01$, respectively). Figure 2 demonstrates that growth hormone infusion resulted in an elevation of plasma growth hormone levels by $20 \pm 2 \mu \mathrm{g} / \mathrm{l}$, while plasma insulin and glucagon remained unchanged. Plasma concentrations of NEFA increased gradually during growth hormone, the increase was significantly higher than in control subjects receiving saline from $75 \mathrm{~min}$ onwards. After heparin injection, mean plasma NEFA increased briskly and similarly in both protocols, within $15 \mathrm{~min}$ by 1.1 and $1.2 \mathrm{mmol} / \mathrm{l}$, respectively. The course of blood glycerol concentrations was similar to that of NEFA. Elevation of growth hormone levels resulted in a higher increase in blood glycerol concentrations than in controls, indicating enhanced lipolysis. After heparin, blood glycerol

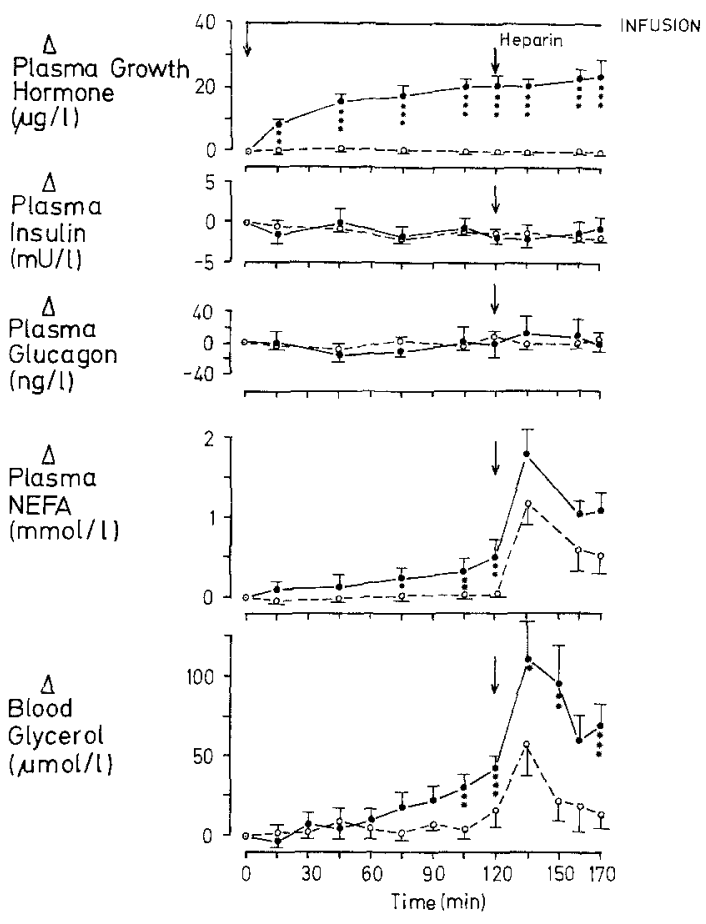

Fig. 2. Changes in the concentrations of growth hormone, insulin, glucagon, NEFA and glycerol during growth hormone infusion (solid line) or saline (dashed line). See legend to Figure 1. Results are expressed as mean \pm SEM. $* p<0,05 ; * * p<0.02 ; * * * p<0.01$ between groups

concentrations increased in a spike-decline pattern in both protocols.

\section{Effect of elevated growth hormone levels on ketone body kinetics and lipolysis during somatostatin-induced insulin deficiency}

Administration of somatostatin alone resulted in a significant elevation of ketone body production after 30 min ( $p<0.001$ compared to the last pre-infusion value, Fig. 3). The increase in ketone body production was significantly greater during growth hormone than during infusion of somatostatin alone from $90 \mathrm{~min}$ onwards. Heparin-induced elevation of plasma NEFA levels resulted in a further acceleration of ketogenesis in both protocols. At the end of the infusions, ketone body production rates during combined infusion of growth hormone and somatostatin had increased more than threefold. Total ketone body uptake increased during both protocols, but the rates were always slightly lower than the concurrent production rates. The metabolic clearance rate of ketone bodies declined similarly in both protocols by approximately 50\%. Total ketone body concentrations increased continuously during both protocols as a result of the positive balance between production and uptake. The $\beta$-hydroxybutyrate/ 
$\Delta$

Total ketone body production

( $\mathrm{umol} \cdot \mathrm{kg}^{-1} \cdot \mathrm{min}^{-1}$ )

$\Delta$

Total ketone body uptake

( $\mathrm{umol} \cdot \mathrm{kg}^{-1} \cdot \mathrm{min}^{-1}$ )

$\Delta$

Total ketone body metabolic clearance $\left(\mathrm{ml} \cdot \mathrm{kg}^{-1} \cdot \mathrm{min}^{-1}\right)$

\section{$\Delta$}

Total ketone body concentration ( $\mathrm{\mu mol} / \mathrm{l})$
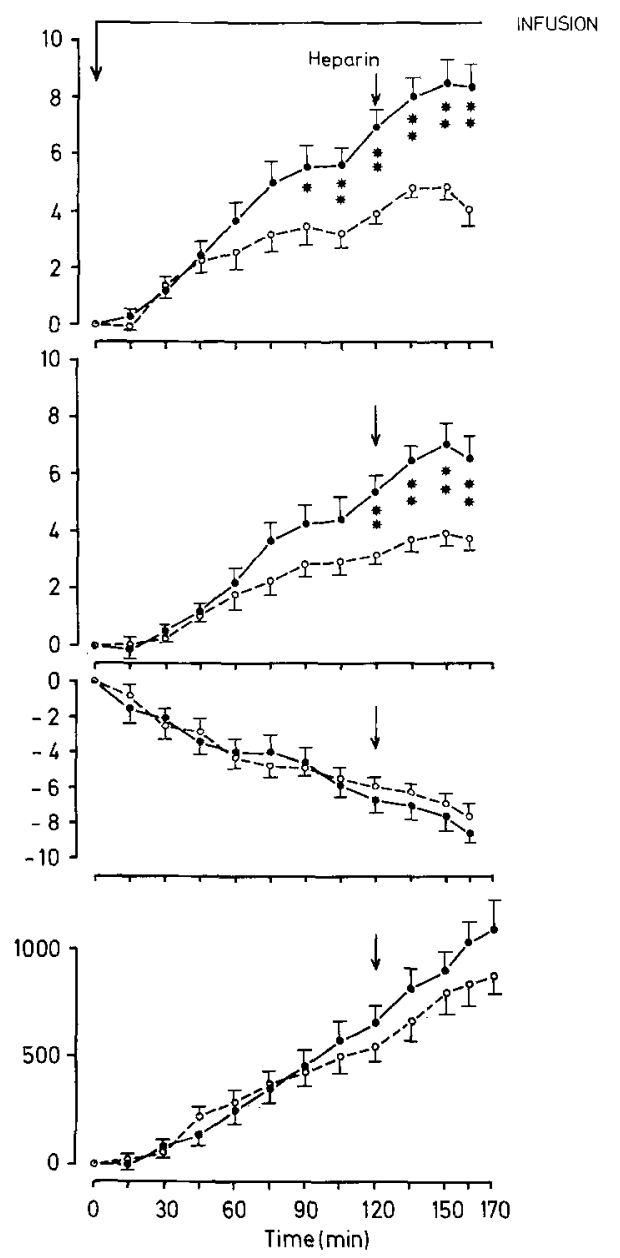

Fig.3. Changes in total ketone body production, uptake, metabolic clearance rate and total ketone body concentration during infusion of somatostatin $\left(6.5 \mu \mathrm{g} \cdot \mathrm{kg}^{-1} \cdot \mathrm{h}^{-1}\right)$ alone (dashed line) or in combination with growth hormone ( $80 \mathrm{ng} \cdot \mathrm{kg}^{-1} \cdot \mathrm{min}^{-1}$, solid line) in normal subjects. At $120 \mathrm{~min}, 5000$ units of heparin were injected. Results are expressed as mean \pm SEM. ${ }^{*} p<0.05 ;{ }^{* *} p<0.01$ between groups

acetoacetate concentration ratio increased similarly during somatostatin with and without growth hormone infusion (from $1.1 \pm 0.2$ to $3.3 \pm 0.3$ in the growth hormone study, $p<0.001$ ).

Figure 4 demonstrates that plasma growth hormone concentration increased during growth hormone infusion by approximately $30 \mu \mathrm{g} / \mathrm{l}$. Infusion of somatostatin alone decreased basal growth hormone levels modestly but significantly $(-0.4 \pm 0.1 \mu \mathrm{g} / 1$ at $45 \mathrm{~min}, p<0,025)$. Infusion of somatostatin lowered plasma concentrations of insulin and glucagon, and increased plasma NEFA and blood glycerol levels significantly in both protocols. Heparin injection resulted in a significant increase in plasma NEFA and blood glycerol concentrations. Growth hormone did not influence plasma NEFA levels but enhanced the heparin-induced increase in blood glycerol concentrations at the last two time points of the study.

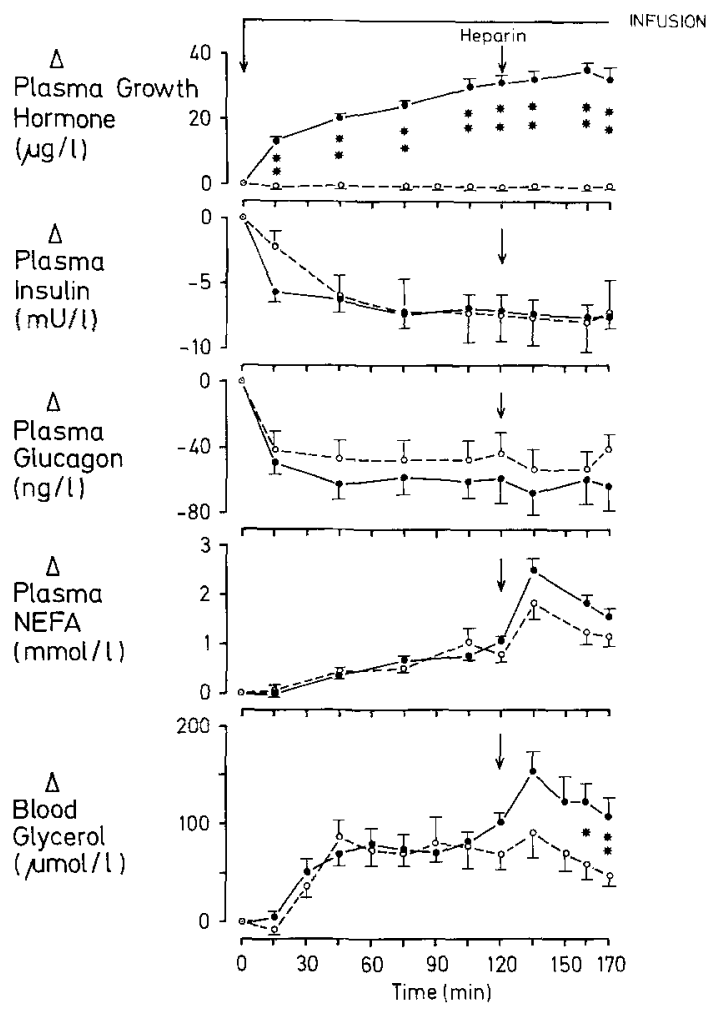

Fig. 4. Changes in concentrations of growth hormone, insulin, glucagon, NEFA and glycerol during infusion of somatostatin alone (dashed line) or in combination with growth hormone (solid line). See legend to Figure 3. Results are expressed as mean \pm SEM. ${ }^{*} p<0.02$; $* * p<0.01$ between groups

\section{Plasma glucose levels}

Plasma glucose levels did not change significantly during $170 \mathrm{~min}$ of growth hormone or saline infusion. Plasma glucose concentrations decreased during somatostatin infusion, with and without addition of growth hormone (from $5.3 \pm 0.2$ and $5.3 \pm 0.2 \mathrm{mmol} / 1$ to nadirs at $90 \mathrm{~min}$ of $3.8 \pm 0.3$ and $3.6 \pm 0.3 \mathrm{mmol} / \mathrm{l}$, respective1y). Thereafter, plasma glucose levels increased gradually reaching values of $4.7 \pm 0.4$ and $4.0 \pm 0.3 \mathrm{mmol} / 1$ at the end of the infusions (NS).

\section{Discussion}

The results of the present study demonstrate that high physiological plasma growth hormone levels exert lipolytic and ketogenic effects in subjects fasted overnight. They explain the previously noted increase in ketone body concentrations during physiological elevation of growth hormone levels as a result of increased ketone body production [12-15]. The concomitant elevation of plasma NEFA levels in normal subjects suggests that the ketogenic effect was secondary to lipolysis and thus to increased substrate supply for ketogenesis. This conclusion is supported by the observation that substrate elevation per se, as observed after heparin injection, resulted in a parallel increase in plasma NEFA levels and 
ketone body production. The effect of growth hormone effect was significant in normal subjects after ketogenesis was supported by increased NEFA concentrations induced by heparin injection.

It was of interest to note that growth hormone infusion during insulin deficiency failed to increase plasma NEFA levels, whereas ketogenesis was significantly enhanced. In addition, the ketogenic response to heparininduced elevation of plasma NEFA levels was significantly greater during growth hormone than during saline administration. This dissociation between plasma NEFA levels and ketogenesis agrees with previous findings of increased ketone body concentrations without concomitant changes in plasma NEFA levels during growth hormone administration in normal [12] and in diabetic [14] subjects. It suggests a direct hepatic ketogenic effect of growth hormone independent of substrate uptake since plasma NEFA levels and, thus presumably, hepatic NEFA uptake $[27,28]$ were unaffected. The issue of the effects of growth hormone on hepatic ketogenesis in vitro is controversial; ketogenic effects were observed in rat liver slices [29] but not in perfused rat liver [30].

The present study employed a tracer technique to determine growth hormone effects on ketone body production and on peripheral uptake. This turned out to be of importance since changes in ketone body production were apparent before significant alterations in ketone body concentrations were observed.

Growth hormone effects on ketone body clearance, and thus on utilisation, were not detected in the present study, in agreement with previous findings in vitro [31]. Thereby we excluded the possibility that early insulinlike [32,33] or late anti-insulin [34] effects of growth hormone affected ketone body utilisation. This was of significance since insulin has been shown to enhance ketone body utilisation in dogs [35]. The same effect may also be the explanation for the decrease of ketone body clearance during somatostatin-induced insulin deficiency in the present study. However it is possible that hyperketonaemia contributed to the decrease in ketone body clearance, since a fall in clearance has previously been observed when ketone body concentrations were raised by ketone body infusions [18]. On the other hand, insulin-like effects of growth hormone on lipolysis, ketone body production or clearance were not detectable in the present study, suggesting that the recently reported early insulin-like effect on hepatic glucose production affected this process selectively [33].

It was of interest to note that during the initial $120 \mathrm{~min}$ of growth hormone infusion, lipolytic effects were detectable in normal subjects but not during acute insulin deficiency. This suggests that the lipolytic effect of growth hormone resulted from its anti-insulin properties [34] which was not apparent in acutely insulin-deficient subjects.

Infusion of somatostatin was used to produce acute insulin deficiency. The validity of this model is support- ed by the fact that direct metabolic effects of somatostatin in liver cells and adipocytes were absent in a previous study in vitro [36]. Additionally, insulin replacement during somatostatin infusion in vivo prevented the somatostatin-induced increase in lipolysis and ketogenesis in normal subjects [37]. Moreover the same study demonstrated that glucagon deficiency during somatostatin infusion did not influence ketogenesis [37].

The elevated growth hormone concentrations achieved during infusion in the present studies resemble those observed during surgical stress [38], exercise [1, 39], poorly controlled diabetés mellitus [2, 3], and alcoholic ketoacidosis [5]. Since in these situations lipolysis and ketone body concentrations are frequently increased, the present results suggest that growth hormone contributes to the development of hyperketonaemia during these conditions. The findings of the present study provide evidence that elevated growth hormone levels during insulin deficiency may accelerate hepatic ketogenesis directly, in addition to a stimulatory effect on lipolysis and substrate-induced enhancement of ketogenesis. Increased rates of ketogenesis during insulin lack result in a further elevation of ketone body levels due to a decrease of the metabolic clearance rate of ketone bodies.

Acknowledgements. The technical assistance of Mrs. R. Meyer and E.Jäggi is greatly appreciated. The secretarial assistance of Miss N. Deola and Mrs. A. Wittker is acknowledged. Supported by grant No. 3.988'80 of the Swiss National Science Foundation.

\section{References}

1. Hansen AP (1970) Abnormal serum growth hormone response to exercise in juvenile diabetics. J Clin Invest 49: 1467-1478

2. Vigneri R, Squatrito S, Pezzino V, Filetti S, Branca S, Polosa P (1976) Growth hormone levels in diabetes. Correlation with the clinical control of the disease. Diabetes 25:167-172

3. Alberti KGMM, Christensen NJ, Iversen J, Orskov H (1975) The role of glucagon and other hormones in the development of diabetic ketoacidosis. Lancet 1: 1307-1311

4. Popp DA, Shah SD, Cryer PE (1982) Role of epinephrine-mediated beta-adrenergic mechanisms in hypoglycemic glucose counterregulation and posthypoglycemic hyperglycemia in insulindependent diabetes mellitus. J Clin Invest 69: 315-326

5. Levy LJ, Duga J, Girgis M, Gordon EE (1973) Ketoacidosis associated with alcoholism in non-diabetic subjects. Ann Intern Med 78: 213-219

6. Best $\mathrm{CH}$, Campbell $\mathbf{J}(1936)$ Anterior pituitary extracts and liver fat. J Physiol (London) 86: 190-203

7. Houssay BA, Anderson E (1949) Diabetogenic action of purified anterior pituitary hormones. Endocrinology 45: 627-631

8. Young PG (1937) Permanent experimental diabetes produced by pituitary (anterior lobe) injections. Lancet $2: 372-374$

9. Luft R, Ikkos D (1958) Effect of growth hormone in hypophysectomised diabetic subjects. Lancet 1: 721-722

10. Raben NS, Hollenberg CH (1959) Effect of growth hormone on plasma fatty acids. J Clin Invest 38: 484 488

11. Felig P, Marliss EB, Cahill GF jr. (1971) Metabolic response to human growth hormone during prolonged starvation. J Clin Invest 50: 411-421

12. Metcalfe P, Johnston DG, Nosadini R, Ørskov H, Alberti KGMM (1981) Metabolic effects of acute and prolonged growth hormone 
excess in normal and insulin-deficient man. Diabetologia 20: $123-128$

13. Sherwin RS, Schulman GA, Hendler R, Walesky M, Belous A, Tamborlane W (1983) Effect of growth hormone on oral glucose tolerance and circulating metabolic fuels in man. Diabetologia 24: $155-161$

14. Gerich J, Lorenzi M, Bier DM, Tsalikian E, Schneider V, Karam JH, Forsham PH (1976) Effects of physiologic levels of glucagon and growth hormone on human carbohydrate lipid metabolism. J Clin Invest 57: 875-884

15. Schade DS, Eaton PR, Peake GT (1978) The regulation of plasma ketone body concentration by counter-regulatory hormones in man. II. Effects of growth hormone in diabetic man. Diabetes 27: 916-924

16. Geigy Ltd, Basel (1960) Geigy Documenta. Scientific Tables, 6th ed.

17. Sonnenberg GE, Keller U (1982) Sampling of arterialized heatedhand venous blood as a noninvasive technique for the study of ketone body kinetics in man. Metabolism 1:1-5

18. Keller U, Sonnenberg GE, Stauffacher W (1981) Validation of a tracer-technique to determine non-steady state ketone body turnover rates in man. Am J Physiol 240: E253-E260

19. Mayes PA, Felts JM (1967) Determination of ${ }^{14} \mathrm{C}$-labelled ketone bodies by liquid-scintillation counting. Biochem $\mathrm{J}$ 102: 230-235

20. Keller U, Cherrington AD, Liljenquist JE (1978) Ketone body turnover and hepatic ketone production in fasted and in diabetic dogs. Am J Physiol 235: E238-E247

21. Van Stekelenburg GJ, De Bruyn JW (1970) A simple gas chromatographic determination of acetone and $\beta$-ketobutyric acid in blood serum by means of head space gas sampling. Clin Chim Acta 28: 233-237

22. Ho RJ (1970) Radiochemical assay of long-chain fatty acids using ${ }^{63} \mathrm{Ni}$ as tracer. Analyt Biochem 36: 105-113

23. Heding LG (1972) Determination of total serum insulin in insulintreated diabetic patients. Diabetologia 8: 260-266

24. Girard J, Baumann JB, Stahl M, Nars PW, Bühler U, Wick H (1971) Experience with insulin-induced hypoglycemia as a provocative test for growth hormone and cortisol secretion in children. Hormones 2: 338-365

25. Aguilar-Parada E, Eisentraut AM, Unger RH (1969) Pancreatic glucagon secretion in normal and diabetic subjects. Am J Med Sci 257: 415-419

26. Holst JJ, Aasted B (1974) Production and evaluation of glucagon antibodies for radioimmunoassay. Acta Endocrinol 77: 715-726

27. Spitzer JJ, Nakamura H, Hori S, Gold M (1969) Hepatic and splanchnic uptake and oxidation of free fatty acids. Proc Soc Exp Biol Med 132: 281-286
28. Basso LV, Havel RJ (1970) Hepatic metabolism of free fatty acids in normal and diabetic dogs. J Clin Invest 49: 537-547

29. Lotspeich WD, Petersen VP (1954) Effect of anterior pituitary growth hormone on synthesis of acetoacetate by surviving slices of rat liver. Am J Physiol 176: 232-238

30. Penhos JC, Wu CH, Lemberg A, Daunas J, Brodoff B, Levine R (1966) The effect of growth hormone on the metabolism of lipids and on urea formation by the perfused rat liver. Metab Clin Exp 15: 1109-1119

31. Bennett LL, Kreiss RE, Hao Li CH, Evans HM (1948) Production of ketosis by the growth and adrenocorticotropic hormones. Am J Physiol 152: 210-215

32. Fineberg SE, Merimee TJ (1974) Acute metabolic effects of human growth hormone. Diabetes 23: 499-513

33. MacGorman LR, Rizza RA, Gerich JE (1981) Physiological concentrations of growth hormone exert insulin-like and insulin antagonistic effects on both hepatic and extrahepatic tissues in man. J Clin Endocrinol Metab 53: 556-559

34. Daughaday WH, Kipnis DM (1966) The growth promoting and anti-insulin actions of somatotropin. Rec Prog Horm Res 22: 49-93

35. Balasse EO, Havel RJ (1971) Evidence for an effect of insulin on the peripheral utilization of ketone bodies in dogs. $\mathrm{J}$ Clin Invest 50: 801-817

36. Cherrington AD, Caldwell MD, Dietz MR, Exton JH, Crofford OB (1977) The effect of somatostatin on glucose uptake and production by rat tissues in vitro. Diabetes 26: 740-748

37. Sonnenberg GE, Stauffacher W, Keller U (1982) Failure of glucagon to stimulate ketone body production during acute insulin deficiency or insulin replacement in man. Diabetologia 23: 94-100

38. Wright PD, Johnston IDA (1975) The effect of surgical operation on growth hormone levels in plasma. Surgery 77:497-486

39. Hunter WM, Fonseka CC, Passmore R (1965) The role of growth hormone in the mobilization of fuel for muscular exercise. Q J Exp Physiol 50: 406-415

Received: 5 April 1983

and in revised form: 30 August 1983

Dr. U. Keller

Division of Endocrinology and Metabolism

Kantonsspital

CH-4031 Basel

Switzerland 